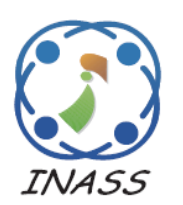

\title{
A Novel Transmission Line's ATC Assessment Method by Considering the Generation Dispatch Limit (GDL) and Renewable Generation Capacity with Power Flow Sensitivity Analysis
}

\author{
Chaisit Wannoi ${ }^{1}$ \\ Narumon Wannoi ${ }^{1}$ \\ Churirut Boonkhun ${ }^{2}$ \\ Chivalai Temiyasathit ${ }^{2}$ \\ Chai Chompoo-inwai ${ }^{1 *}$ \\ ${ }^{I}$ Electrical Engineering Department, Faculty of Engineering, \\ King Mongkut's Institute of Technology Ladkrabang, Bangkok,10550, Thailand \\ ${ }^{2}$ Faculty of Engineering, King Mongkut's Institute of Technology Ladkrabang, Bangkok, 10550, Thailand \\ * Corresponding author's Email: chaichompoo@gmail.com
}

\begin{abstract}
This paper presents a novel transmission line's Availability Transfer Capability (ATC) assessment method by considering the Generation Dispatch Limit (GDL) and renewable generation capacity. This method has calculated the power remaining from the Total Transfer Capability (TTC). The TTC in this study is the total generation available declaration of all maximum Generation Shift Factor (GSF) generations to transfer power on transmission line depended on the Power Purchase Agreement of each power generation and of each renewable generation integrated in the system. The maximum GSF generations are defined by using the power sensitivity analysis. Results of this novel method are compared with the traditional transmission line's thermal limit method. Main findings showed that newly proposed method for ATC calculation can be used for the ATC assessment of transmission line and can be a good predictive index to protect power system's voltage stability issue. Moreover, it can be applied to the congestion management scheme with the optimal primary respond generation to control the stability of power transfer on the transmission line.
\end{abstract}

Keywords: Available transfer capability (ATC), Generation dispatch limit (GDL), Renewable, Voltage stability, Power flow sensitivity.

\section{Introduction}

The Availability Transfer Capability (ATC) assessments and power congestion management of transmission lines in power system are the two key significant issues in power system secure operation. If the generations or the transmission lines have highly transferred power over load, it will have damaged and carried the system to unstable such as authors [1-3] have studied power failure risk assessment and recommendation for power system security enhancement. Then, it is very important to have assessment of system stability. Especially, the Transmission line's ATC assessment and management to protect the transmission line congestion as same as authors' studies results $[4,5]$.
Moreover, authors in [6, 7] used the power sensitivity analysis to power system severity analysis and determination the ATC with power transfer distribution factor (PTDF).

According to the requirements of the North American Power Reliability Council (NERC) [8], the ATC assessment studies have been carried out to evaluate the transmission capacity of the important transmission lines such as the Inter-tied transmission line' s ATC evaluation by $[9,10]$ or Power system Interconnection by [11]. In addition, there are new techniques in [12] used probabilistic considering existing and future wind generation resources. Also, there are many studies' results in congestion protection planning such as installation of FACTs by authors [13-15], installation the Phase Monitor 
Unit (PMU) by author [16], to reduce the system's power loss by author [17]. In addition, research to support power system control with utilized an optimal generation dispatch are found in [18] and power system stability enhancement planning by authors [19-21].

Typically, power transfer on each transmission line will have a highly dominant generation groups to control, regulate and transfer power for support when power flow patterns are changing. Normally, The ATC assessment will define the Total Transfer Capability (TTC) under the thermal limit of transmission line, voltage stability limit and generation stability limit but this paper has purposed to define the TTC with the generation dispatch limit (GDL) of all highly important generations to transfer power on transmission line and also considering the behavior of renewable generations integrated in the studied system. The highly important generations are defined by using the Generation Shift Factor (GSF) data from power flow sensitivity analysis which all highly generations are the maximum GSF power sensitivity generation group. Then, if the maximum GSF generation group is limited with GDL, The Automatic Generation Control system (AGC) will not be able to dispatch generation to increase load for support load demand increasing in that time. And, if load keeps continuous increasing, it will affect to the bus voltage decrease until system voltage instability happened [22]. This study use a modified Thailand's power system during peak load data in 2015-16 for a system base case [23] as shown in Fig.1 and Table 1. In Thailand, the generation dispatch in power system is controlled by The AGC under National Control Center (NCC) by the Short-term Planning Department. The AGC will dispatch generation base on the Available Declaration Statement (ADS) data from each power plants except those Very Small Power Producer (VSPP) due to the VSPP is nonfirm power plant. The ADS of each power plant will be different under the Power Purchase Agreement (PPA). Then, all main power plants (EGAT, IPP and SPP) must submit the ADS for the next day planning to the Short Planning Department follow scheme as show in Fig. 2.

Most of the previous research work to estimate ATC will mainly focus on Generation Capacity Curve (GCC), however, none of them mention and take into consideration of Availability Declaration Statement of each Generations under the PPA. Therefore, this paper, proposed a novel ATC assessment method to calculate the power capacities remaining from the TTC of all maximum GSF

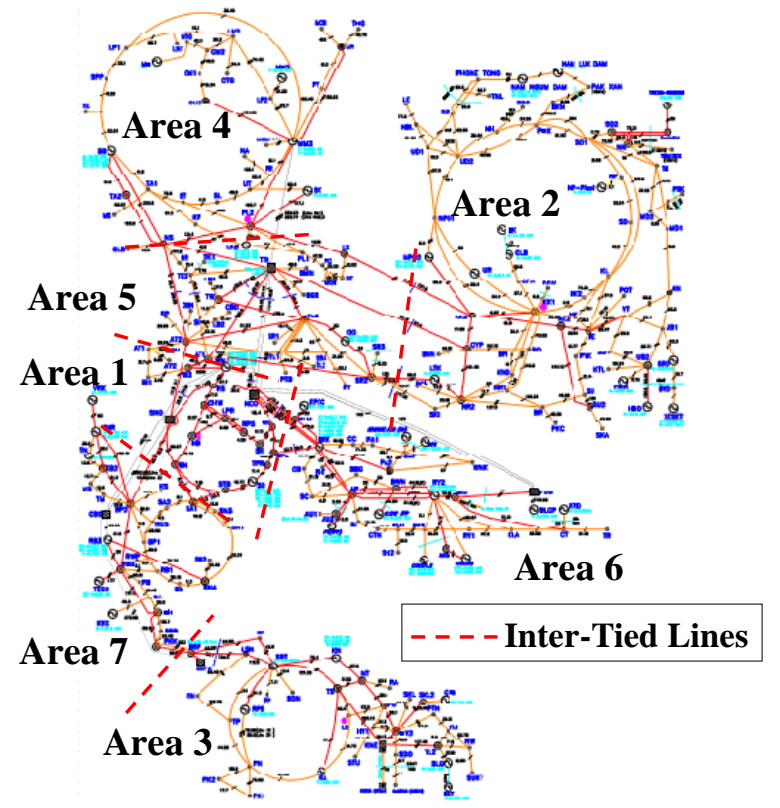

Figure.1 Thailand power system overview

Table 1. Modified-Thailand system's data, year 2014-16

\begin{tabular}{|c|c|c|c|c|}
\hline Area & Gen. & Loads & Losses & Int-Lines \\
\hline 1 & 2379.00 & 9821.98 & 84.00 & -7527.64 \\
\hline 2 & 2073.22 & 2924.00 & 178.54 & -1029.32 \\
\hline 3 & 1661.92 & 2001.66 & 56.48 & -396.22 \\
\hline 4 & 3329.57 & 2727.37 & 113.93 & 490.26 \\
\hline 5 & 3870.11 & 2862.14 & 70.70 & 937.28 \\
\hline 6 & 9748.80 & 3677.23 & 46.70 & 6024.87 \\
\hline 7 & 4381.13 & 2836.20 & 44.16 & 1500.77 \\
\hline Total & 27443.75 & 26848.58 & 595.17 & 0 \\
\hline
\end{tabular}

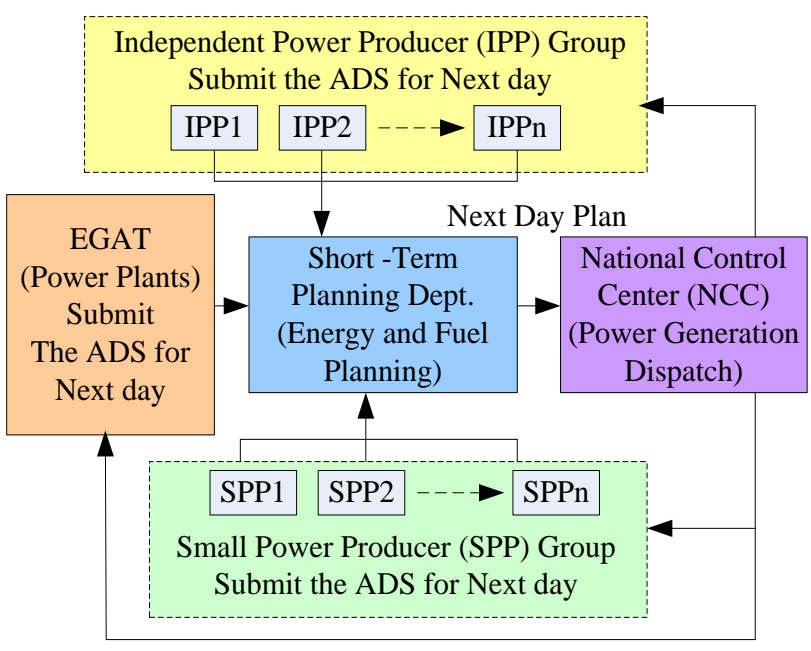

Figure.2 Energy planning and power generation dispatch scheme overview in Thailand

generations group to transfer on transmission line including the renewable generation's capacities which integrated in the studied system. It should be noted that in a study, the renewable generations are 
VSPP which typically have limit installed capacity of less than $9 \mathrm{MW}$.

\section{The power sensitivity analysis $[6,7]$}

In this paper, the power sensitivity analysis uses generation shift factor (GSF) to analysis the power transfer on transmission line which the GSF results are the calculation of changing of generation on line power flow in system. The changing generation can present with the Eq. (1):

$$
a l i=\frac{\Delta f l}{\Delta P i}
$$

Where ali is the linear Generation Shift Factor for the lth line for a change in output of lth generator, $\Delta f l$ is the MW change in power flow in the lth line and $\Delta P i$ is the change in generation at the itl line.

The generation variation at the itl bus is picked up by the reference bus. The new power flow in each line can presents in Eq. (2):

$$
f_{l}^{\text {new }}=f_{l}^{\text {old }}+a_{l i} \Delta p_{i} ; \forall l=1,2, \ldots, L
$$

Then from Eq. (2) can presents as Eq. (3):

$$
f_{l}^{\text {new }}=f_{l}^{\text {old }}-a_{l i} P_{i}^{\text {old }} ; \forall l=1,2, \ldots, L ;\left[\because \Delta P_{i}=-P_{i}^{\text {old }}\right]
$$

Where $f_{l}^{\text {new }}$ is the new power flow in each line, $f_{l}^{\text {old }}$ is the power flow on the lth line before the itl generator outage, $P_{i}^{\text {old }}$ is the output of the ith generator before fault

\section{The available transfer capability}

Normally, The ATC assessment considered the TTC base on the Transmission line's thermal limit, Voltage limit and Generation limit. The TTC of each transmission line will not constant. It will keep real time changing follow power system condition. In this paper, the TTC is defined as a minimum of either thermal limit or voltage limit or generator limit at each power system condition as show in Fig.3. The study results have defined total transfer capability limit base on availability declaration statement of each generation unit in system. The North American Electric Reliability Council (NERC) [8] has defined the ATC to assessment of the transfer capability remaining of each transmission lines in the transmission line network
Power Flow (MW)

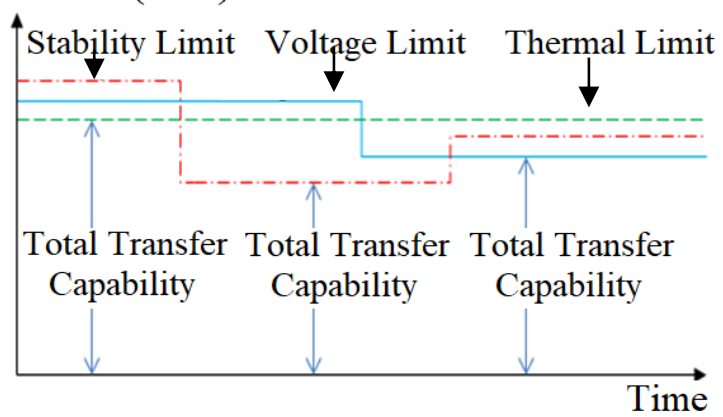

Figure. 3 The total transfer capability limit at each power system condition

of power system. The Total Transfer Capability (TTC) can presents in Eq. (4):

$$
T T C=A T C+T R M+(E T C+C B M)
$$

In this paper, the margins of TRM and CBM are not considered and used the NERC ATC terminology. Given, the ETC is as same as the real power flow in MVA. Then, The ATC here can present in Eq. (5):

$$
A T C=T T C-E T C
$$

Where TTC is Total Transfer Capability, ATC is Available Transfer Capability, TRM is Transfer Reliability Margin, ETC is Existing Transfer Capability, $C B M$ is Capability Benefit Margin

\section{The available declaration limit}

The generation control system controlled power generation base on the availability declaration statement of each power plant following the power plant purchase agreement (PPA). The essential data of the availability declaration statement has shown in Table 2 which is generation limits of power plants for generation dispatching with Automatic Generation Control system. When comparing the ADS data with generator capacity limit, it found that the generation availability declaration limit is less

Table 2. Definition of availability declaration statement

\begin{tabular}{|c|c|c|}
\hline Number & Description & Unit \\
\hline 1 & $\begin{array}{c}\text { Power availability } \\
\text { (Min., Max.) }\end{array}$ & MW \\
\hline 2 & $\begin{array}{c}\text { Reactive power limit } \\
\text { (Min., Max.) }\end{array}$ & MVAR \\
\hline 3 & Primary respond & MW \\
\hline 4 & Five minute respond & $\mathrm{MW}$ \\
\hline 5 & Fifteen minute respond & $\mathrm{MW}$ \\
\hline 6 & Loading rate & $\mathrm{MW} / \mathrm{min}$ \\
\hline 7 & De-loading rate & $\mathrm{MW} / \mathrm{min}$ \\
\hline
\end{tabular}




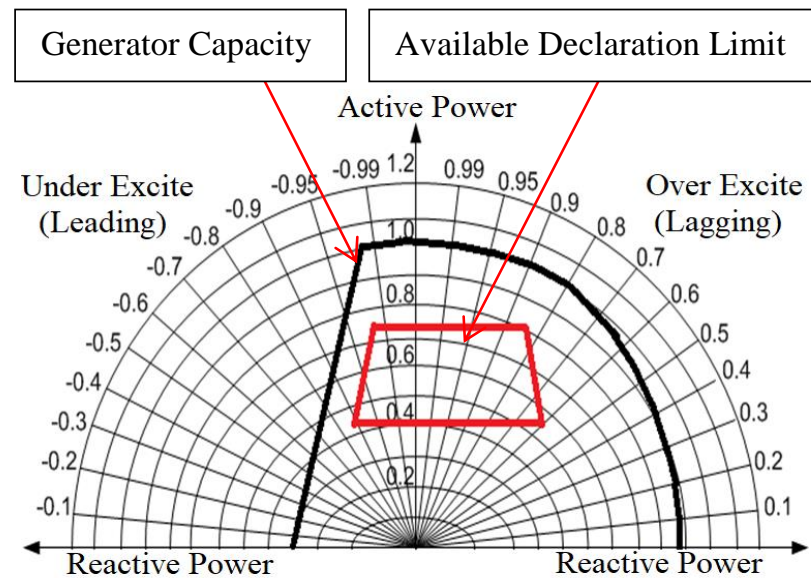

Figure.4 The ADS limit on generator capacity curve

than the generator capacity limit meaning that the actual maximum power transferrable of each generation will be limited according to the value of ADS data as show in Fig.4.

From Fig.4, the generation control system cannot dispatch over the availability declaration limit. That mean, the availability declaration limit is the generation dispatch limit (GDL) of the generation control system. In this study, therefore, use the generation dispatch limit to define the TTC which is a newly proposed limit for the ATC calculation of transmission lines.

\section{A novel ATC assessment method}

The purpose of this study is to present a new method of the ATC assessment to be a predictive index preventing the power system from unstable condition. This new scheme was presented in Fig.5. Fig. 5 shows the simple power system which is supply power from a generator to the load by transfer power on double transmission lines.

\subsection{A newly proposed ATC assessment method}

The maximum power transfer or the TTC of this system will be limited by any of these three limits consisting of Transmission line's thermal limit, Voltage limit or Generation limit. Typically, the Generation limit is the rotor angle stability limit or the Generator capacity limit then the ATC of this system and can presents by Eq. (6):

$$
A T C=G E N_{\text {CAPACITY }}-G E N_{\text {OUTPUT }}
$$

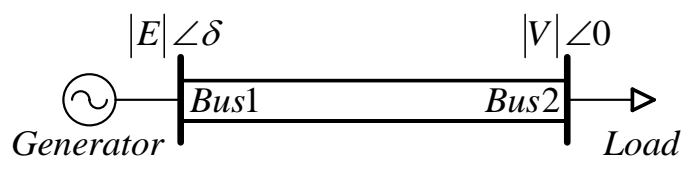

Figure.5 The simple power system
Where $G E N_{\text {CAPACITY }}$ is the total transfer capability (TTC), GEN

The AGC system will control or dispatch the generation to supply power to the grid following the availability declaration of each power plant under PPA. Then, this is a maximum power generation dispatch limit under the AGC system. In the large scale power system, there are many generations and transmission lines which will be difficult to define the TTC each of transmission line. Then, in this research will use power flow sensitivity analysis to find the highly important generations to transfer power on transmission line by using the GSF data. The group of highly important generations is defined as the maximum GSF generation group to respond for transfer power on real time when load demand in system variation. Other than this generation group can carry to set for system congestion protection. Then, The TTC of transmission line in a study is the consumption of the maximum GSF generation group to transfer power on each of transmission line. Then, A Novel ATC assessment calculation incases not considering the renewable generation capacities integrated at a study bus can presents in Eq. (7):

$$
\begin{aligned}
& A T C_{\text {Novel }}=\sum_{G_{1}}^{G_{n}} \text { GDL.Main_Gen }{ }_{G S F_{M A X} G r o u p} \\
& -\sum_{G_{1}}^{G_{n}} \text { Output.Main_Gen }{ }_{G S F_{M A X} G r o u p}
\end{aligned}
$$

However, for a case of considering the renewable generation capacities integrated at a studied system, ATC can be newly proposed presented in eq. (8):

$$
\begin{gathered}
\text { ATC }_{\text {Novel }}=\left[\begin{array}{l}
\sum_{G_{1}}^{G_{n}} \text { GDL.Main_Gen } \\
\text { GSF }_{M A X} \text { Group } \\
+\sum_{G_{1}}^{G_{n}} \text { Renewable }_{G S F_{M A X} \text { Group }}
\end{array}\right] \\
-\left[\begin{array}{l}
\sum_{G_{1}}^{G_{n}} \text { Output.Main_Gen } \\
\text { GSF } F_{M A X} \text { Group } \\
+\sum_{G_{1}}^{G_{n}} \text { Output.Renewable_Gen }
\end{array}\right]
\end{gathered}
$$

Where GDL.Main_Gen $n_{G S F_{M A X} \text { Group }}$ is the maximum GSF Main generation group, Renewable GSF $_{M A X}$ Group is the maximum $G S F$ renewable generation group, Output.Main_Gen GSF $_{M A X}$ Group is the real power supply of the maximum GSF generation group, Output.Renewable_Gen ${ }_{G S F_{M A X} G r o u p}$ is the real power supply of the maximum $G S F$ renewable generation group. 


\subsection{The congestion protection}

The congestion protection in this paper use for protects transmission lines overloading by set the optimal primary respond generations. These respond generations have been considered from the MW impaction generation of the maximum GSF generation group. The MW impaction calculation can present in Eq. (9):

$$
M W_{\text {impaction }}=\text { Gen.Output }_{(M W)} \times G S F_{(\text {Generator })}
$$

Where Gen.Output $(M W)$ is the real power supply of generator, $G S F_{\text {(Generator) }}$ is the GSF factor value of generator.

\section{The simulation and study results}

In this section, there are two main significant parts of results. The first part is to indicate and show how important of these highly important generators to transfer power on transmission line and the second part is to reveal the newly transmission line's ATC assessment by comparing the traditional way of ATC calculation and the newly proposed method which consider the effect of renewable generation integrated into the system.

\subsection{The group of highly important generations are dominant on transferring power in each transmission line}

This study result indicates how significant of the key generations impact to power-transfer on the critical transmission lines. The test simulation will check the respond of generators incase restoration of line on multi-lines bus was overloaded. The study results compare the variation of power-transfer in case of the high capacity generator in area 2, 4 and 5 are shedding. Those all result are shown in Table 3. The group of Maximum-GSF generation on line no. 2803-2806 is shown in Table 4. The study results test in case the transmission line no. 2803-2806 circuit 2 was tripped which effect to line no. 28032806 circuit 1 is overload.

Table 4 shows the group-list of Maximum GSF of generators according to the MW impaction ranking from high to low. Those all transmission line connected to bus no. 2803 are shown in Fig.6.

Table 3. The high generator capacity in area 2, 4 and 5

\begin{tabular}{|c|c|c|c|c|}
\hline \multicolumn{5}{|c|}{ High Generator Capacity each of Area } \\
\hline Area & $\begin{array}{c}\text { Gen } \\
\text { Number }\end{array}$ & $\begin{array}{c}\text { Gen } \\
\text { MW }\end{array}$ & $\begin{array}{c}\text { Min } \\
\text { MW }\end{array}$ & $\begin{array}{c}\text { Max } \\
\text { MW }\end{array}$ \\
\hline 2 & 2011 & 250 & 100 & 250 \\
\hline 4 & 4048 & 295 & 120 & 300 \\
\hline 5 & 5043 & 240 & 106 & 265 \\
\hline
\end{tabular}

Table 4. The group of Max-GSF generator on transmission line no. 2803-2806 (the important line)

\begin{tabular}{|c|c|c|c|c|}
\hline \multicolumn{5}{|c|}{ Generator Sensitivities } \\
\hline No. & $\begin{array}{c}\text { Gen } \\
\text { Number }\end{array}$ & $\begin{array}{c}\text { GSF } \\
\text { Sensitivity }\end{array}$ & $\begin{array}{c}\text { Gen } \\
\text { MW }\end{array}$ & $\begin{array}{c}\text { MW } \\
\text { Impaction }\end{array}$ \\
\hline 1 & 2021 & 0.861 & 120 & 103.32 \\
\hline 2 & 2022 & 0.861 & 120 & 103.32 \\
\hline 3 & 2024 & 0.861 & 120 & 103.32 \\
\hline 4 & 2025 & 0.861 & 120 & 103.32 \\
\hline 5 & 2023 & 0.861 & 110 & 94.71 \\
\hline 6 & 2026 & 0.861 & 110 & 94.71 \\
\hline
\end{tabular}

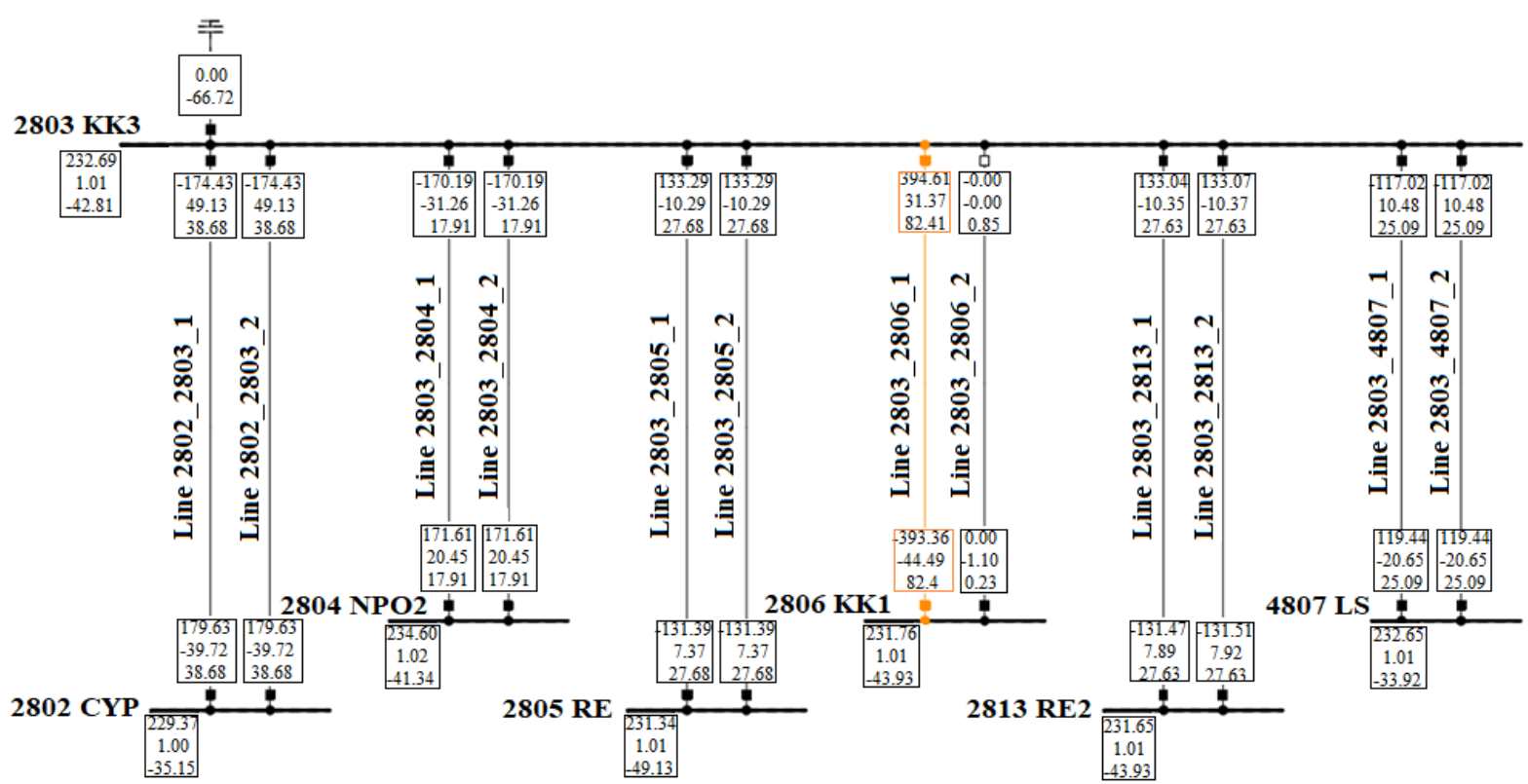

Figure.6 Major transmission lines connected on bus no. 2803 


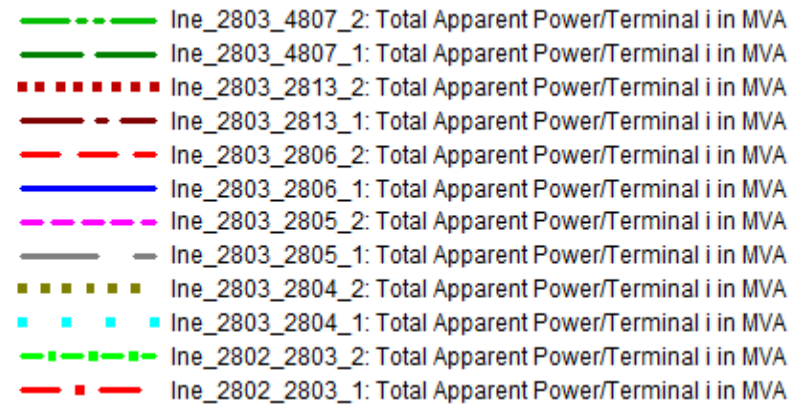

Figure.7 The Power transfer each of transmission line connected bus no. 2803

Apparent Power (MVA)

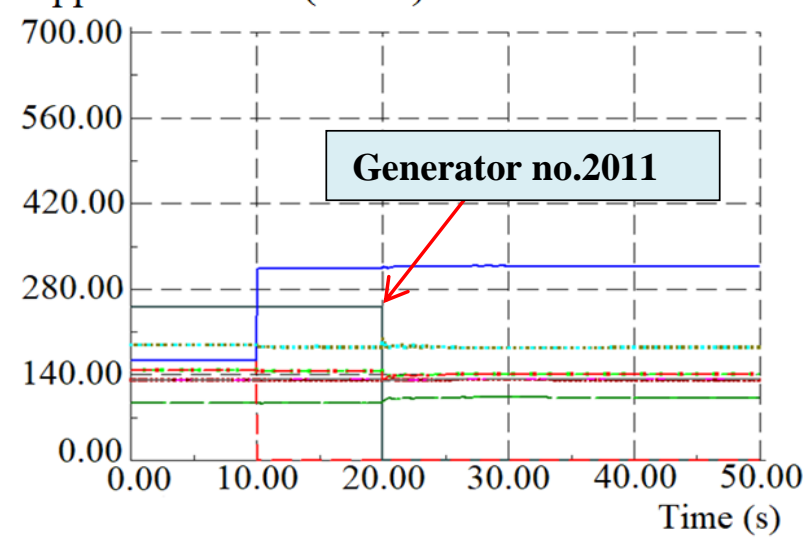

Figure. 8 The shedding of generator no.2011

Apparent Power (MVA)

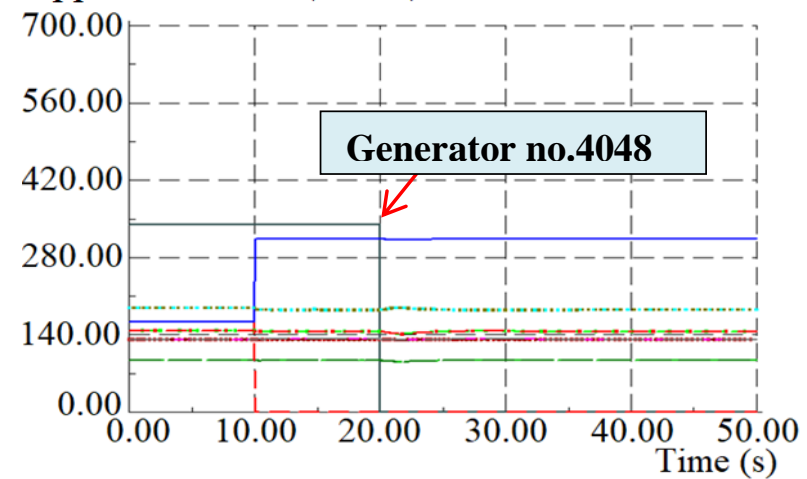

Figure.9 The shedding of generator no.4048

Apparent Power (MVA)

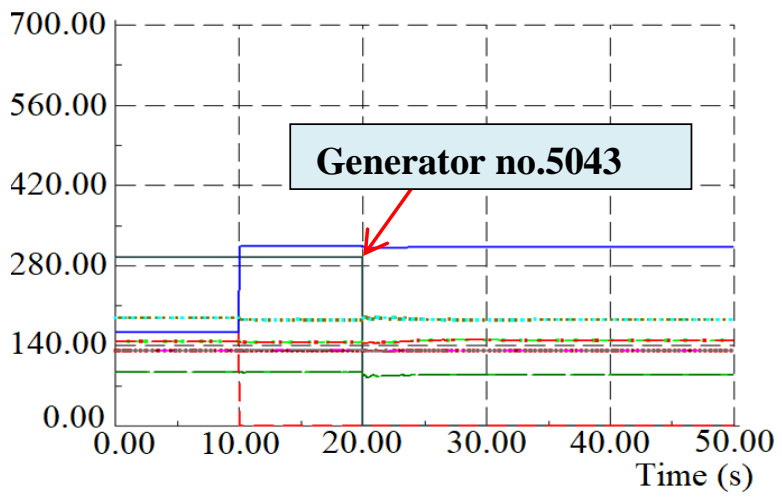

Figure.10 The shedding of generator no.5043
Apparent Power (MVA)

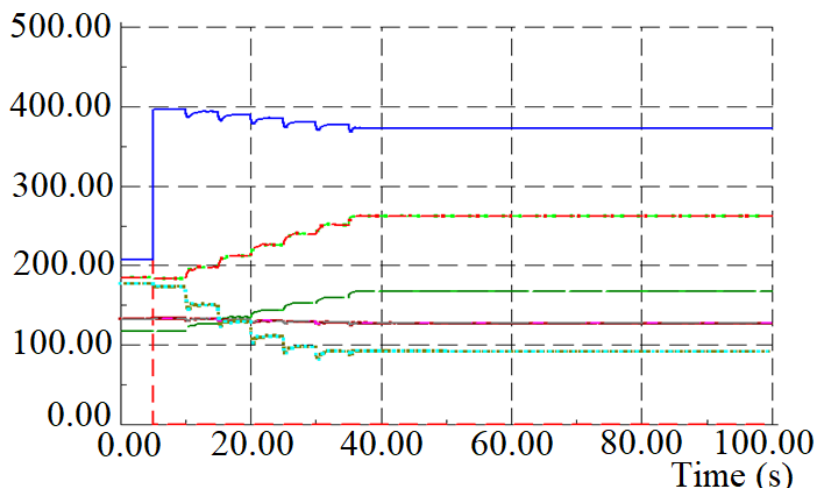
Time (s)

—- Ine_2803_4807_2: Total Apparent Power/Terminal i in MVA - Ine_2803_4807_1: Total Apparent Power/Terminal i in MVA

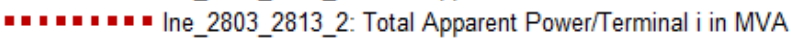
- Ine_2803_2813_1: Total Apparent Power/Terminal i in MVA — - Ine_2803_2806_2: Total Apparent Power/Terminal i in MVA - Ine_2803_2806_1: Total Apparent Power/Terminal i in MVA - - - - - Ine_2803_2805_2: Total Apparent Power/Terminal i in MVA - Ine_2803_2805_1: Total Apparent Power/Terminal i in MVA | | | | | | | | Ine_2803_2804_2: Total Apparent Power/Terminal i in MVA " | " " " | Ine_2803_2804_1: Total Apparent Power/Terminal i in MVA - $-\because-\|-$ Ine_2802_2803_2: Total Apparent Power/Terminal i in MVA - - Ine_2802_2803_1: Total Apparent Power/Terminal i in MVA

Figure.11 The power transfer of lines connected on bus no. 2803 when the Max-GSF generation changing

The study results are shown in Fig.7-12. The total simulation time is 50 second with following scenarios. At the time 10 second, line no. 2803-2806 circuit 2 was tripped and at the time 20 second, all generators in table 3 are shredded respectively.

Figs. 8-10 show the power transfer of lines connected on bus no. 2803. We found that when those generators no. 2011, 4048 and 5043 are shedding, they do not affect to power transfer on transmission line no. 2803-2806 circuit 1. However, for the cast of the Maximum GSF generators, it they are decreasing the output power, it will directly affect to the power transfer on this transmission lines significantly as that shown in Fig.11-12. Therefore, one can conclude that this generator group has highly important transfer the power on this transmission line. The scenario setting of generation capacities decreasing will be decreased follow MW impaction as shown in table 4 every 5 second by start at 10 second. From the above result, therefore, we can find that the responsiveness of generations can be used for the transmission lines congestion protection by defined the primary respond generation when load increasing or decreasing. In the case of these generations are limited to supply power, it will create insufficient power transfer to support the increasing demand. This situation can cause bus voltage decrease and affect the stability of power system. 
Active Power (MW)

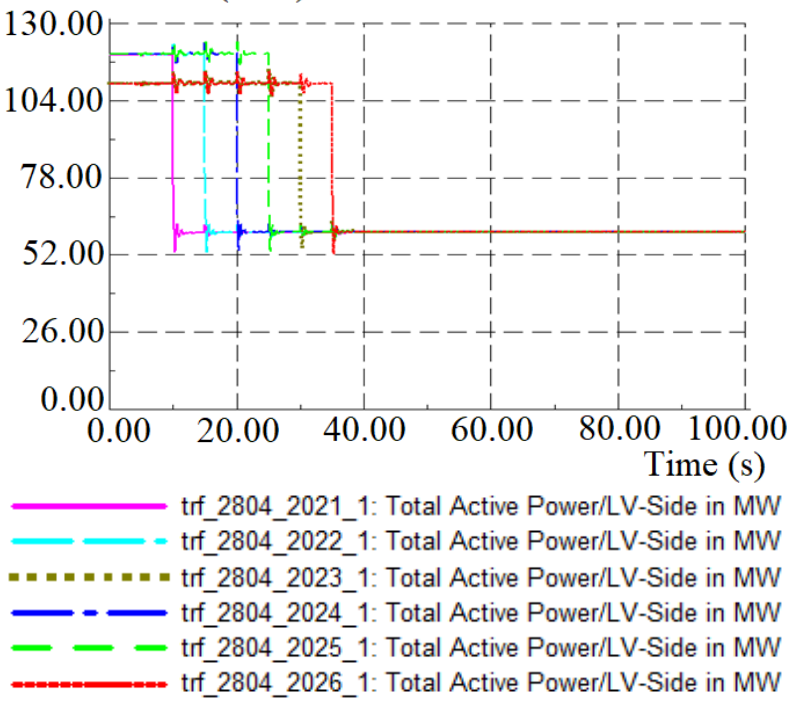

In this study, we compare two ATC assessment methods: the first one is to consider ATC base on thermal limit, and second one is considering Generation Dispatch Limit as show in Table 5 and 6. Table 5 shows the Generation Dispatch Limit each generator to transfer power on this transmission line follow Table 4 . The Table 6 shows the line capacity by considering the thermal limit of transmission line no. 2803-2806. The comparison results between a new ATC assessment and the ATC assessment base on thermal limit without considering renewable generation can show in Table 7.

The study results in Table 7 found a new ATC assessment technique has high TTC to the transfer power but the ATC has less than the ATC assessment base on thermal limit.

Figure.12 The Max. GSF generation output decreasing

Table 5. The Generation Dispatch Limit of the Max-GSF generators on transmission line no. 2803-2806

\begin{tabular}{|c|c|c|c|c|c|c|c|c|c|}
\hline \multicolumn{3}{|c|}{ Generator Output } & \multicolumn{4}{|c|}{ Generation Dispatch Limit } & \multirow{2}{*}{$\begin{array}{c}\text { Max } \\
\text { (MVA) }\end{array}$} & \multirow{2}{*}{$\begin{array}{c}\text { Use } \\
\text { (MVA) }\end{array}$} & \multirow{2}{*}{$\begin{array}{c}\text { Remain } \\
\text { (MVA) }\end{array}$} \\
\hline Number & Gen MW & Gen Mvar & Min MW & Max MW & Min Mvar & Max Mvar & & & \\
\hline 2021 & 120 & 45 & 48.4 & 121 & -30.25 & 45 & 129 & 123 & 1 \\
\hline 2022 & 120 & 45 & 48.4 & 121 & -30.25 & 45 & 129 & 123 & 1 \\
\hline 2023 & 110 & 45 & 45.2 & 113 & -28.25 & 45 & 122 & 114 & 3 \\
\hline 2024 & 120 & 45 & 48.4 & 121 & -30.25 & 45 & 129 & 123 & 1 \\
\hline 2025 & 120 & 45 & 48.4 & 121 & -30.25 & 45 & 129 & 123 & 1 \\
\hline 2026 & 110 & 45 & 45.2 & 113 & -28.25 & 45 & 122 & 114 & 3 \\
\hline
\end{tabular}

Table 6. The transmission line no. 2803-2806 capacity base on thermal limit

\begin{tabular}{|c|c|c|c|c|c|c|c|}
\hline \multicolumn{7}{|c|}{ Line Capacity with Thermal limit considering } \\
\hline Line no & Circuit & From MW & From Mvar & From MVA & Lim MVA & Remain MVA & Max Percent \\
\hline $2803-2806$ & 1 & 396.2 & 36.2 & 397.8 & 476.9 & 79.1 & 84.4 \\
\hline
\end{tabular}

Table 7. ATC assessment result without renewable consideration

\begin{tabular}{|l|c|c|c|}
\hline \multicolumn{4}{|c|}{ The ATC assessment comparison } \\
\hline Considering Method & TTC & ETC & ATC \\
\hline Thermal limit & 476.9 & 397.8 & 79.1 \\
\hline Generation Dispatch Limit & 760 & 750 & 10 \\
\hline
\end{tabular}

\subsection{The Voltage stability and ATC assessment results when considering the renewable generation capacity integration.}

The study results are focus on voltage stability study and the transmission line's ATC assessment on the multi-lines with critical voltage bus when load demand is increasing. The tested-system has integrated the renewable 9MW at all $115 \mathrm{KV}$ buses in area 2. Then, the load demand factor step for increasing is $0.01 \mathrm{pu}$. (one percentage of total loads in area 2).
The testing will increase load continuous until power system reach the unstable stage by used repeated power flow technique. The study result found the multi-line bus no. 2707 has occurred critical voltage in area 2 at load factor 0.09 as show in Fig.13.

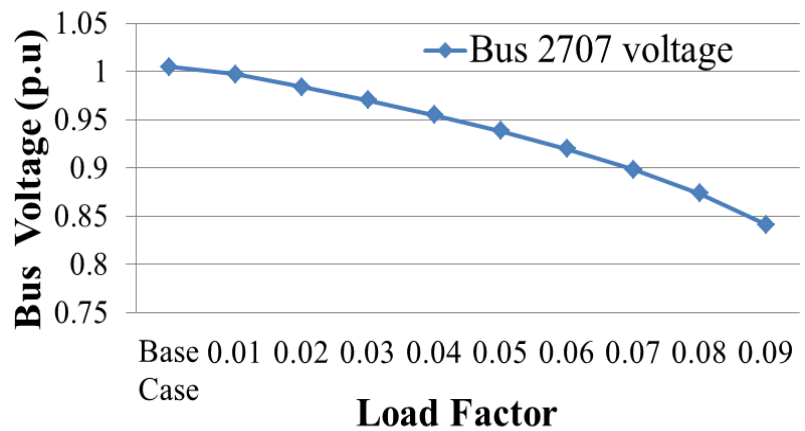

Figure.13 The voltage variation on bus 2707 under voltage stability limit 


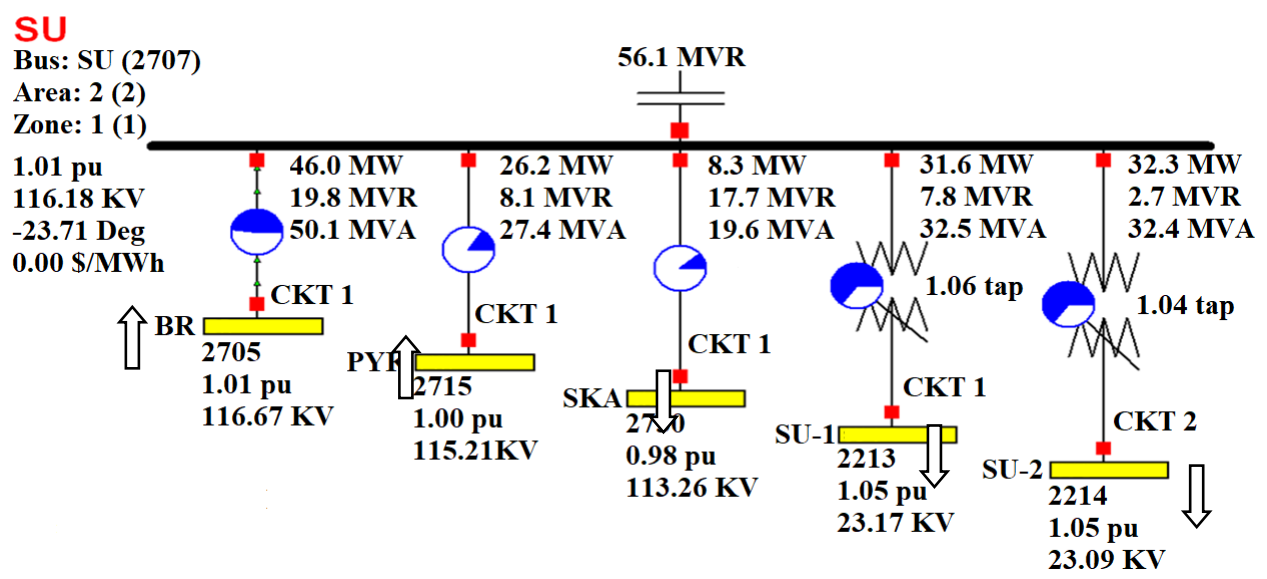

Figure.14 The Multi-line bus no.2707

Table 8. The group of Max-GSF generator with Primary respond generation on line no. 2705-2707

\begin{tabular}{|c|c|c|c|c|c|c|c|c|c|}
\hline \multicolumn{4}{|c|}{ Generator Output } & \multicolumn{3}{c|}{ Generation Dispatch Limit } & Max & Uses & Remain \\
\hline \multirow{2}{*}{ Number } & $\begin{array}{c}\text { Gen } \\
\text { MW }\end{array}$ & $\begin{array}{c}\text { Gen } \\
\text { Mvar }\end{array}$ & $\begin{array}{c}\text { Min } \\
\text { MW }\end{array}$ & $\begin{array}{c}\text { Max } \\
\text { MW }\end{array}$ & $\begin{array}{c}\text { Min } \\
\text { Mvar }\end{array}$ & $\begin{array}{c}\text { Max } \\
\text { Mvar }\end{array}$ & MVA & MVA & MVA \\
\hline 2011 & 249.67 & 53.1 & 100 & 250 & -62.5 & 125 & 279.51 & 255.25 & 24.25 \\
\hline 2012 & 249.67 & 54.23 & 100 & 250 & -62.5 & 125 & 279.51 & 255.25 & 24.25 \\
\hline
\end{tabular}

Table 9. The group of Max-GSF generator with renewable generation on line no. 2705-2707

\begin{tabular}{|c|c|c|c|c|c|c|c|c|c|}
\hline \multicolumn{3}{|c|}{ Generator Output } & \multicolumn{3}{c|}{ Generation Dispatch Limit } & Max & Uses & Remain \\
\hline Number & $\begin{array}{c}\text { Gen } \\
\text { MW }\end{array}$ & $\begin{array}{c}\text { Gen } \\
\text { Mvar }\end{array}$ & $\begin{array}{c}\text { Min } \\
\text { MW }\end{array}$ & $\begin{array}{c}\text { Max } \\
\text { MW }\end{array}$ & $\begin{array}{c}\text { Min } \\
\text { Mvar }\end{array}$ & $\begin{array}{c}\text { Max } \\
\text { Mvar }\end{array}$ & MVA & MVA & MVA \\
\hline 2705 & 9 & 0 & 0 & 9 & -3.87 & 3.87 & 9.8 & 9 & 0.8 \\
\hline 2706 & 9 & 0 & 0 & 9 & -3.87 & 3.87 & 9.8 & 9 & 0.8 \\
\hline
\end{tabular}

Table 10. The group of Max-GSF generator (Top 10 list) with primary respond generation on line no. 2715-2707

\begin{tabular}{|c|c|c|c|c|c|c|c|c|c|}
\hline \multicolumn{3}{|c|}{ Generator Output } & \multicolumn{3}{c|}{ Generation Dispatch Limit } & Max & Uses & Remain \\
\hline Number & $\begin{array}{c}\text { Gen } \\
\text { MW }\end{array}$ & $\begin{array}{c}\text { Gen } \\
\text { Mvar }\end{array}$ & $\begin{array}{c}\text { Min } \\
\text { MW }\end{array}$ & $\begin{array}{c}\text { Max } \\
\text { MW }\end{array}$ & $\begin{array}{c}\text { Min } \\
\text { Mvar }\end{array}$ & $\begin{array}{c}\text { Max } \\
\text { Mvar }\end{array}$ & MVA & MVA & MVA \\
\hline 2003 & 11.98 & 6 & 4.8 & 12 & -3 & 6 & 13.42 & 13.40 & 0.02 \\
\hline 2004 & 11.98 & 6 & 4.8 & 12 & -3 & 6 & 13.42 & 13.40 & 0.02 \\
\hline 2005 & 11.98 & 6 & 4.8 & 12 & -3 & 6 & 13.42 & 13.40 & 0.02 \\
\hline 2040 & 7.29 & -4 & 4.5 & 13 & -4 & 6 & 14.32 & 8.32 & 6.00 \\
\hline 2040 & 1.65 & -0.75 & 1.2 & 3 & -0.75 & 1.5 & 3.35 & 1.81 & 1.54 \\
\hline 2040 & 7.09 & -4 & 4.5 & 13 & -4 & 6 & 14.32 & 8.14 & 6.18 \\
\hline 2051 & 33.96 & 5.03 & 13.6 & 34 & -8.5 & 17 & 38.01 & 34.33 & 3.68 \\
\hline 2052 & 33.96 & 5.03 & 13.6 & 34 & -8.5 & 17 & 38.01 & 34.33 & 3.68 \\
\hline 2053 & 33.96 & 5.03 & 13.6 & 34 & -8.5 & 17 & 38.01 & 34.33 & 3.68 \\
\hline 2054 & 33.96 & 5.03 & 13.6 & 34 & -8.5 & 17 & 38.01 & 34.33 & 3.68 \\
\hline 2063 & 61.65 & 6.9 & 25.2 & 70 & -15.75 & 31.5 & 76.76 & 62.03 & 14.73 \\
\hline 2064 & 61.65 & 6.9 & 25.2 & 70 & -15.75 & 31.5 & 76.76 & 62.03 & 14.73 \\
\hline
\end{tabular}

Table 11. The group of Max-GSF generator with renewable generation on line no. 2715-2707

\begin{tabular}{|c|c|c|c|c|c|c|c|c|c|}
\hline \multicolumn{4}{|c|}{ Generator Output } & \multicolumn{3}{c|}{ Generation Dispatch Limit } & Max & Uses & Remain \\
\hline \multirow{2}{*}{ Number } & $\begin{array}{c}\text { Gen } \\
\text { MW }\end{array}$ & $\begin{array}{c}\text { Gen } \\
\text { Mvar }\end{array}$ & $\begin{array}{c}\text { Min } \\
\text { MW }\end{array}$ & $\begin{array}{c}\text { Max } \\
\text { MW }\end{array}$ & $\begin{array}{c}\text { Min } \\
\text { Mvar }\end{array}$ & $\begin{array}{c}\text { Max } \\
\text { Mvar }\end{array}$ & MVA & MVA & MVA \\
\hline 2715 & 9 & 0 & 0 & 9 & -3.87 & 3.87 & 9.8 & 9 & 0.8 \\
\hline
\end{tabular}

The Multi-line bus no. 2707 in Fig.14 has two incoming lines then this is considered as a critical line and need to find the ATC assessment. Then, the Max-GSF generations of each transmission line in International Journal of Intelligent Engineering and Systems, Vol.12, No.5, 2019 case not consider and in case consider the renewable generation capacity show in Table 8-11. The ATC study results each condition show in Table 12-13 and Fig.15-18. 
Table 12. The ATC assessment comparison results without consider the renewable generation integration

\begin{tabular}{|c|c|c|c|c|c|c|c|}
\hline \multirow{2}{*}{ Line No. } & \multirow{2}{*}{ Considering Method } & \multicolumn{3}{|c|}{ Base case } & \multicolumn{3}{c|}{ at Load Factor 0.09 } \\
\cline { 3 - 8 } & & TTC & ETC & ATC & TTC & ETC & ATC \\
\hline \multirow{2}{*}{$2705-2707$} & Thermal limit & 104.2 & 50.1 & 54.1 & 104.2 & 53 & 51.2 \\
\hline \multirow{2}{*}{$2715-2707$} & Generation Dispatch Limit & 559.02 & 510.75 & 48.27 & 559.02 & 559.02 & 0.00 \\
\cline { 2 - 8 } & Thermal limit & 179.1 & 27.4 & 151.7 & 179.1 & 30.9 & 148.2 \\
\cline { 2 - 8 } & Generation Dispatch Limit & 395.49 & 329.81 & 65.68 & 395.49 & 341.00 & 54.49 \\
\hline
\end{tabular}

Table 13. The ATC assessment comparison results with consider the renewable generation integration

\begin{tabular}{|c|c|c|c|c|c|c|c|}
\hline \multirow{2}{*}{ Line No. } & \multirow{2}{*}{ Considering Method } & \multicolumn{3}{|c|}{ Base case } & \multicolumn{3}{c|}{ at Load Factor 0.09 } \\
\cline { 3 - 8 } & & TTC & ETC & ATC & TTC & ETC & ATC \\
\hline \multirow{2}{*}{$2705-2707$} & Thermal limit & 104.2 & 50.1 & 54.1 & 104.2 & 53 & 51.2 \\
\cline { 2 - 8 } & Generation Dispatch Limit & 560.62 & 510.75 & 49.87 & 560.62 & 559.02 & 1.6 \\
\hline \multirow{2}{*}{$2715-2707$} & Thermal limit & 179.1 & 27.4 & 151.7 & 179.1 & 30.9 & 148.2 \\
\cline { 2 - 8 } & Generation Dispatch Limit & 396.29 & 329.81 & 66.48 & 396.29 & 341.00 & 55.29 \\
\hline
\end{tabular}

The study results in Fig. 15-16 are the ATC assessments in case of not consider the renewable generation capacity in system. The finding showed that the ATC of transmission line no. 2705-2707 with a new technique limited the power transfer at load factor 0.09 as same as voltage limit while the ATC assessment with Transmission line's thermal limit are not limit. For, the ATC assessment of transmission line no. $2715-2707$ is not limit. Then, the transmission line no. 2705-2707 must improve the voltage for protect system unstable.

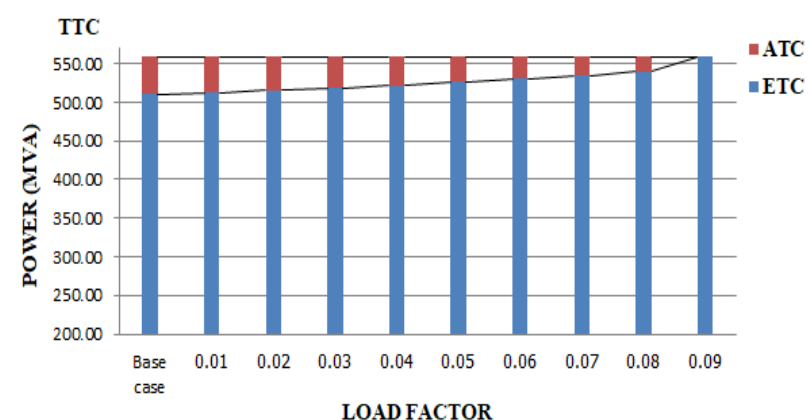

Figure.15 The ATC and ETC changing on line no. 27052707 without renewable generation capacity

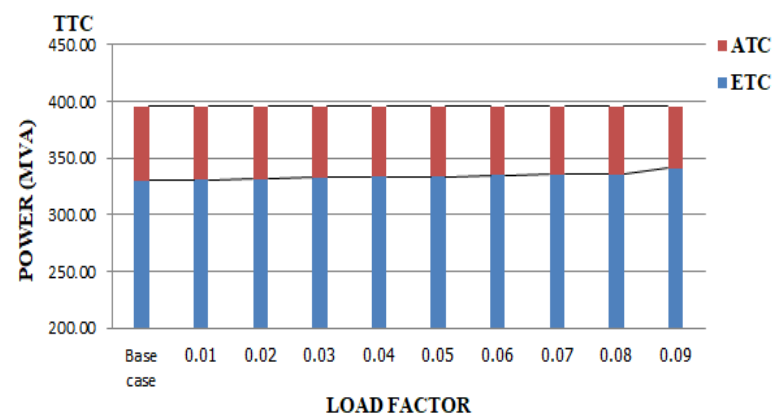

Figure.16 The ATC and ETC changing on line no. 27152707 without renewable generation capacity
For, the study results in Fig. 17-18 are the ATC assessments in case of considering the renewable generation integrated in power system. The finding showed the ATC of transmission line no. 2705-2707 and no. 2715-2707 are increased little power transfer limits. Then, when power system operation during peak load period, if there are renewable generations integrate into power system, it will increase the ATC of transmission lines or power transfer limit in power system which can enhance power system security.

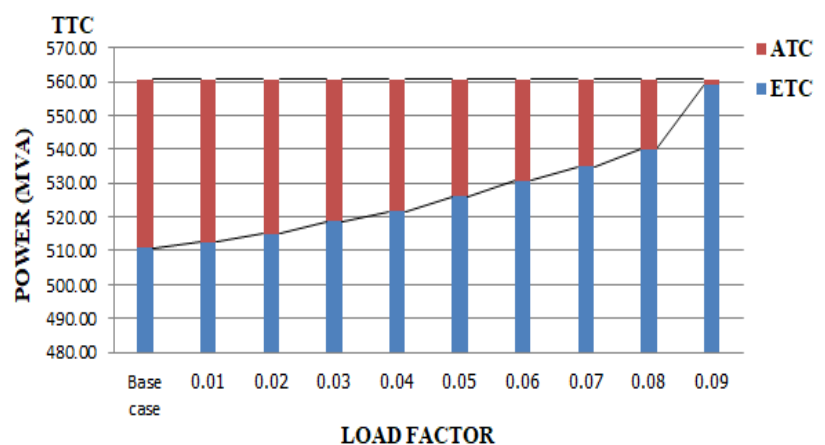

Figure.17 The ATC and ETC changing on line no. 27052707 include renewable generation capacity

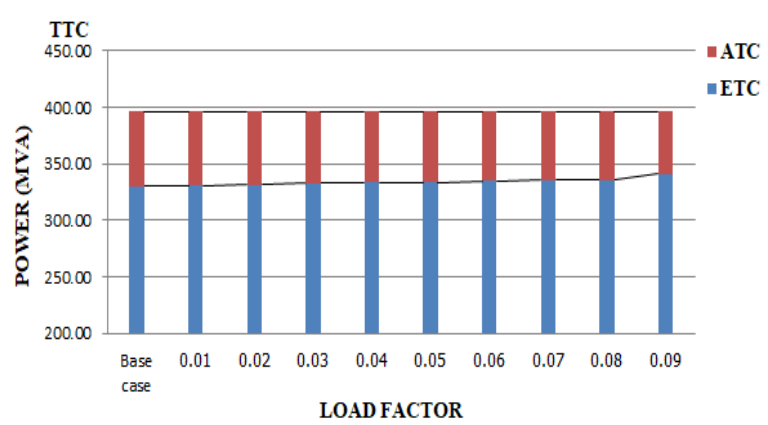

Figure.18 The ATC and ETC changing on line no. 27152707 include renewable generation capacity 


\section{Conclusions}

The transmission line' ATC assessment and voltage stability protection have highly important in power system control and planning. If the generations or the transmission lines have highly transferred power over load, it will have damaged and carried the system to loss security. Then, this study has proposed a novel transmission line's availability transfer capability (ATC) assessment method by consider the generation dispatch limit (GDL) and renewable generation capacity integrated in system. The ATC calculation in this study is the determination of the new TTC, which is the total of maximum capacity of the maximum GSF generation group that is important to transfer power on the transmission line. The Maximum capacity of each generator will reference to the Availability Declaration Statement (ADS) according to the power purchase agreement (PPA). Which, this is the generation dispatch limit (GDL) on the practical power system control.

The study results found this a new method can enhance and reinforce the ATC of transmission line in a large power system as well as voltage limit or thermal limit or generation stability limit techniques.

Moreover, this novel ATC assessment method cans applicate to predict or use to be a predictive index for protect the system voltage instability and system congestion protection. However, in case of congestion control for transmission lines connected to multi-lines bus, one can use the maximum GSF generation group to control power flow on transmission line. However, those multi-lines buses must have more than one incoming line from the different power source. The reason behind is because if one of transmission lines connected on multi-line bus has decreases power transfer, the power flow must transfer from another available transmission line to compensate the power. Therefore, this is the key criteria for the transmission line's congestion control and these newly proposed methodologies will reinforce power system security enhancement.

\section{References}

[1] Q. Zhou, X. Li, J. Liao, and T. Xiong, "Power failure risk assessment and management based on stochastic line failures in distribution network including distributed generation", IEEJ Transaction on Electrical and Electronic Engineering, pp. 1303-1312, 2018.

[2] Y. Shu and Y. Tang, "Analysis and Recommendations for the Adaptability of
China's Power System Security and Stability Relevant Standard", CSEE Journal of Power and Energy Systems, Vol. 3, No.4, 2017.

[3] C. Wannoi, N. Wannoi, and C. Chompooinwai, "An Impact Study and Operation Recommendation in Peak Load Period after Solar Power Integration to Northeastern Power System in Thailand", In: Proc. of International Conference on Electrical Engineering, 2015.

[4] A. Sadiq and M. Nwohu, "Evaluation of Inter Area Available Transfer Capability of Nigeria 330KV Network", International Journal of Engineering and Technology, Vol.3 No.2, 2013.

[5] C. Chompoo-inwai, C. Yingvivatanapong, P. Faungfoo, and W.J. Lee, "Transmission Congestion Management during Transition Period of Electricity Deregulation in Thailand", IEEE Transaction on Industrial Application, Vol. 43, pp.1483-1490, 2007.

[6] S. Ravindra, V.C. Veera Reddy, and S. Sivanagaraju, "Power System Severity Analysis under Generator Outage Condition", International Journal of Advanced Research in Electrical, Electronics and Instrumentation Engineering, Vol. 4, 2015.

[7] N.D. Ghawghawe and K.L. Thakre, "Application of Power Flow Sensitivity Analysis and PTDF for Determination of ATC", IEEE, 2016.

[8] North American Electric Reliability Council (NERC), Available Transfer Capability Definitions and Determination, NERC Report, 1996.

[9] J. Liu and C. Chu, "Iterative Distributed Algorithms for Real-Time Available Transfer Capability Assessment of Multi Area Power Systems", IEEE Transaction on Smart Grid, Vol. 6, No. 5, 2015.

[10] Y. Ohsaki, M. Hitosugi, S. Iwamoto, H. Hosogoe, and M. Matsumoto, "An efficient tieline ATC calculation method with N-1 contingencies", International Journal of Smart Grid and Clean Energy, 2013.

[11] S. Hyun-Il, K Jin-O, and B. In-Su, "Evaluation of Optimal Transfer Capability in Power system interconnection", In: Proc. of IEEE 
Bucharest Power Tech Conference, Bucharest, Romania, 2009.

[12] P. Du, W. Li, X. Ke, N. Lu, O. Ciniglio, and M. Colburn, P. Anderson, "Probabilistic-Based Available Transfer Capability Assessment Considering Existing and Future Wind Generation Resources", IEEE Transaction on Sustainable Energy, Vol. 6, No.4, 2015.

[13] T. Nireekshana, G. Kesava Rao, and S. Siva Naga Raju, "Enhancement of ATC with FACTS devices using Real-code Genetic Algorithm", International Journal of Electrical Power and Energy Systems, pp.1276-1284, 2012.

[14] C. Wannoi, S. Bunjongjit, and C. Chompooinwai, "A Proper Location FACTS Device Placement and Primary Generation Response Definition for Multi-Lines Buses Security Enhancement under Contingency Analysis", In: Proc. of International Conference on Electrical Engineering, 2015.

[15] M. Khaburi and M. Haghifam, "A Probabilistic Modelling base Approach for Total Transfer Capability Enhancement using FACTS devices", International Journal of Electrical Power and Energy Systems, pp.12-16, 2010.

[16] F. Yu, C. Booth, A. Dysko, and Q. Hong, "Wide-Area Backup Protection and Protection Performance Analysis Scheme using PMU data", International Journal of Electrical Power and Energy Systems, pp.630-641, 2009.

[17] D. Nataraj, R. Loganathan, M. Veerasamy, and V. Jawalkar, "Optimizing Radial Distribution System for Minimizing Loss Reduction and Voltage Deviation Indices Using Modified Grey Wolf's Algorithm", International Journal of Intelligent Engineering and Systems, Vol.11, No.6, pp. 177-189, 2018.

[18] U. Chhor, U. Leeton, and K. Chayakulkheeree, "Probabilistic Optimal Power Dispatch Considering Price-Based Real-Time Demand Response", International Journal of Intelligent Engineering and Systems, Vol.12, No.1, pp. 201-210, 2019.

[19] C. Chompoo-inwai, W.J. Lee, P. Fuangfoo, M. Williams, and J.R. Liao, "System Impact Study for the Interconnection of Wind Generation and
Utility System", IEEE Transactions on industry applications, Vol.41, No.1, 2005.

[20] C. Chompoo-inwai and W.J. Lee, "Reactive Compensation Technique to Improve the RideThrough Capability of Wind Turbine during Disturbance", IEEE Transaction on Industrial Application, Vol. 41, No. 3, pp.666-672, 2005.

[21]C. Wannoi, A. Khumdee, N. Wannoi, and C. Chompoo-inwai, "An Optimum Technique for Renewable Power Generations Integration to Power System using Repeated Power Flow Technique Considering Voltage Stability Limit", Procedia Computer Science, Vol.86, pp.357-360, 2016.

[22] P. Kundur, N. J. Balu, and M. G. Luuby, Power System Stability and Control, 1994.

[23] Energy Policy and Planning Office Ministry of Energy, Thailand Power Development Plan, 2015. 